\title{
in the final analysis
}

"History will be kind to me for I intend to write it."

Volume 72

Number 2
Each year, I prepare a report for the TMS Board of Directors that presents highlights from the previous year's inventory of activities. Naturally, I'm happy when the history is a good one (the Board references it in developing my performance review). Do I ever try to leverage my role as historian to cook the narrative and benefit myself? I sincerely hope not as I like to think that I have a compulsion for ethics, rigor, and accuracy in myself and others. That disposition greatly overwhelms any impulses that might otherwise lead to glossing over or camouflaging a disappointing outcome. I'd rather just own any mistake, learn from it, and move on.

Of course, I especially enjoy learning from successes, and I'm pleased to report that TMS can inventory several notable ones from 2019. I offer the following for your consideration:

1. The TMS Annual Meeting \& Exhibition is a (the?) preferred destination for the international materials community. From TMS2015 to TMS2020, the number of abstracts submitted has grown $17 \%$, with more than 5,100 abstracts being proposed for TMS2020. Even allowing for rejections and cancellations, that's still a heck of a lot of podium time and poster presentations. At TMS2020, we'll be accommodating an expansion of posters with a tuned-up poster forum featuring electronic presentations.

2. Our friend $\mathrm{JOM}$ is increasingly the place to publish. There is a lot of competition in the journal community, with Journal Citation Reports tracking 293 scholarly materials science journals and 76 in metallurgy. JOM ranks 142 and 17, respectively, with JOM's Impact Factor having grown from 1.757 to 2.305 over five years. From 2015-2019, the number of papers published annually has grown from 447 to 667 -a roughly $50 \%$ increase, but you knew based on how the journal dents your mailbox monthly.

3. TMS takes conduct and harassment very seriously. At TMS2019, the Board of Directors adopted a Meetings Code of Conduct and an updated Anti-harassment Policy. Over the course of the year, the Board carefully researched, deliberated upon, and acted on three separate situations triggered by these policies. The Board's decision-making, while difficult, stayed true to our goal of making TMS events both welcoming and inclusive.

4. TMS is committed to the TMS Aspires strategic plan. For example, our goal of being "the society that envisions, defines, and enables the future" saw the Society issue three well-received studies over the course of 2019: Verification and Validation of Computational Models Associated with the Mechanics of Materials, Metamorphic Manufacturing: Shaping the Future of On-Demand Components, and Creating the NextGeneration Materials Genome Initiative Workforce.

5. TMS is acutely mission-oriented but dollars are an important enabler. We are projecting TMS's revenue to grow from $\$ 7.2 \mathrm{M}$ in 2016 to $\$ 9.2 \mathrm{M}$ in 2020 , an almost $28 \%$ increase. Likewise, our operating reserves project to grow from roughly $\$ 4.7 \mathrm{M}$ to $\$ 6.1 \mathrm{M}$ over the same period. Operating reserves protect us in the event of a rainy day and are leveraged to develop new initiatives. Members can be assured that the Society's finances are managed responsibly.

I could also mention that membership increased and that the TMS Foundation had a strong year, but I don't yet have the final numbers to toot about just yet. We also just debuted new recurrent meetings on High Entropy Alloys and Materials in Nuclear Energy Systems (with the American Nuclear Society). Those are strong pillars for the future.

Oh yes, MS\&T19 outperformed expectations in Portland, Oregon, and the unified partnership is very enthusiastic to conduct the event in Pittsburgh later this year. We have a record number of symposia submitted for MS\&T20, and I suspect that it is going to be one of the success stories that I feature in next year's report—if you help us make that happen.

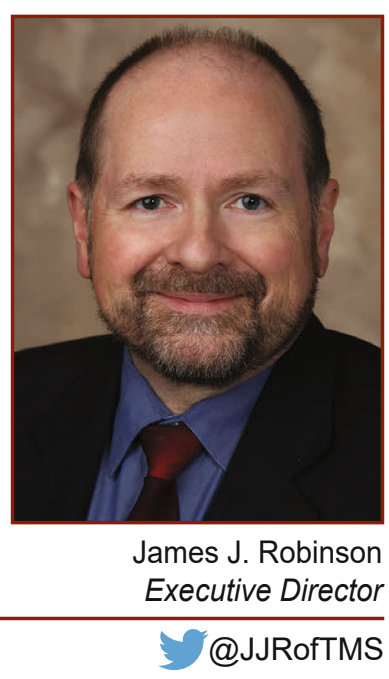

"Do I ever try

to leverage my

role as historian

to cook the

narrative and

benefit myself?" 